\title{
Pengaruh pijat oksitosin terhadap frekuensi His, durasi His pada ibu inpartu di BPM ASRI Tuban
}

\author{
Umu Qonitun, ${ }^{1 *}$ Mariyatul Qiftiyah, ${ }^{2}$ \\ ${ }^{1,2}$ Program Studi D-III Kebidanan STIKes Nahdlatul Ulama Tuban, Indonesia
}

\begin{abstract}
Childbirth is very important observation his and see the frequency and duration his so that the childbirth when i will still continue smooth, either on primi and multi 1.If long childbirth when i normal taking place not so potential possible problems occurring.And if uterine contractions not so veins in the no placenta, is maximum this resulting in bleeding nifas 2 . The purpose of this research to know his influence massage oksitosin against frequency and duration of his on the inpartu in of west beautiful tuban. This study experimental design ( pre static-group comparation design the, kohort ) population all the normal in maternity of west beautiful tuban february - may 2019 some 60 respondents, using systematic or random sampling techniques of sampling the total sample 52 respondents divid ed into groups respondents control ( 26 ) and the experiment respondents ( 26 ). Massage oksitosin and independent variable dependent variable his frequency and duration of his.Data analysis use independent sampel vs spss t-test with 23 . In the majority of respondents ( 1453,8 ) get percent of his 410 times in minutes and there an effect massage oksitosin against frequency his on the inpartu also in beautiful tuban. 2019 yearsThe duration of his experiment in the most respondents percent 16 ( 61,5 ) get duration his \& gt; 40 second and there an effect oxyitocin massage for the duration of his on the inpartu. Influence massage oksitosin his against frequency and duration of his on the inpartu in beautiful, of west tuban is expected in especially midwives health workers applying massage oxyitocin when $\mathrm{i}$ in childbirth how shall facilitate the delivery process and reduce the maternal mortality.
\end{abstract}

\begin{abstract}
Keywords: oxyitocin massage; frequency HIS; duration his
Persalinan sangat penting dilakukan observasi HIS yaitu dengan melihat frekuensi dan durasi His sehingga proses persalinan kala I akan berlangsung dengan mulus, baik pada primi maupun multi (Astuti, 2013). Jika lama persalinan kala I berlangsung tidak normal maka masalah potensial dimungkinkan terjadi. Dan jika kontraksi uterus tidak baik maka pembuluh darah di daerah plasenta tidak terjepit dengan maksimal, hal ini yang mengakibatkan perdarahan postpartum (Studi, Keperawatan, Perintis, \& Bakti, 2016). Tujuan penelitian ini untuk mengetahui pengaruh pijat oksitosin terhadap frekuensi his dan durasi his pada ibu inpartu di BPM ASRI Tuban.. Desain penelitian ini pra eksperimental (static-group comparation design) dengan pendekatan kohort, populasinya seluruh ibu bersalin normal di BPM ASRI Tuban bulan februari - mei 2019 sejumlah 60 responden, dengan menggunakan teknik sampling sistematik random sampling didapatkan jumlah sampel 52 responden dibagi menjadi kelompok kontrol ( 26 responden) dan kelompok eksperimen ( 26 responden). Variabel independen Pijat oksitosin sedangkan variabel dependen frekuensi his dan durasi his. Analisa data menggunakan independent sample t-Test dengan SPSS Vs 23. Frekuensi his pada kelompok eksperimen sebagian besar 14 responden (53,8\%) mendapatkan Frekuensi his 4 kali dalam 10 menit dan
\end{abstract}

\footnotetext{
"Corresponding Author: Umu Qonitun (email: hafizh.hak@gmail.com),
} 
ada Pengaruh Pijat Oksitosin terhadap Frekuensi His pada Ibu inpartu di BPM ASRI Tuban Tahun 2019. Sedangkan durasi his pada kelompok eksperimen sebagian besar 16 responden (61,5\%) mendapatkan durasi his $>40$ detik dan ada Pengaruh Pijat Oksitosin terhadap durasi His pada Ibu inpartu di BPM ASRI Tuban Tahun 2019. Terdapat pengaruh pijat oksitosin terhadap Frekuensi his dan durasi his pada ibu inpartu di BPM ASRI Tuban, diharapkan pada tenaga kesehatan khususnya para bidan dapat menerapkan pijat oksitosin pada persalinan kala I yang mana akan memperlancar proses persalinan dan dapat mengurangi kejadian kematian ibu.

Kata kunci: pijat oksitosin; frekuensi HIS; durasi HIS; persalinan normal

\section{Pendahuluan}

Persalinan adalah proses alamiah atau fisiologi yang akan dialami oleh setiap wanita (Mochtar, 2011). Persalinan sangat penting dilakukan observasi HIS yaitu dengan melihat frekuensi dan durasi His sehingga proses persalinan kala I akan berlangsung dengan normal (A.R, Pamingki Ritno, Yuniastini, 2016). Proses pengeluaran plasenta biasanya akan terjadi pengumpulan darah dibelakang plasenta dan membantu pengeluaran plasenta (Astuti, 2013). Apabila lama persalinan kala I berlangsung tidak sempurna atau melebihi waktu yang semestinya maka masalah potensial akan terjadi (Riyanto, 2014). Jika uterus berkontraksi yang tidak sempurna sehingga pembuluh darah yang berada di daerah plasenta tidak terjadi penjepitan dengan maksimal, akhirnya akan mengakibatkan perdarahan yang berat (Studi et al., 2016).

Menurut penelitian Berdasarkan hasil penelitian kelompok eksperiment, pijat oksi- tosin dapat merangsang hormon oksitosin yang menyebabkan kontraksi uterus sehingga mempermudah lahirnya plasenta (Studi et al., 2016). Sedangkan kelompok kontrol hampir setengahnya pengeluaran plasenta 12 menit, dikarenakan kontraksi uterus yang kurang kuat untuk melepaskan plasenta (Sofia, 2017).

Faktor yang mempengaruhi frekuensi his dan durasi his selain keadaan fisik ibu juga dapat dipengaruhi oleh faktor psikologis meliputi kecemasan menjelang persalinan (Cunningham, 2015). pada ibu hamil akan muncul pertanyaan dan bayangan apakah dapat melahirkan normal, bagimana cara mengejan, apakah bayi akan lahir dengan selamat (Kemenkes RI, 2013). Kecemasan merupakan unsur kejiawaan yang menggambarkan perasaan, keadaan emosional yang dimiliki oleh seseorang pada saat menghadapi kenyataan atau kejadian dalam hidupnya(varney, 2010). 
Pengaruh pijat oksitosin terhadap frekuens His, durasi His ...

Kecemasan dan ketakutan ibu tersebut menyebabkan penurunan hormon oksitosin sehingga plasenta tidak dapat keluar segera setelah bayi dilahirkan (Qonitun \& Betalia, 2018). pemberian uterotonik yang tidak tepat waktunya yang juga dapat menyebabkan serviks kontrkasi dan menahan plasenta, serta pemberian anastesi terutama yang melemahkan kontraski uterus (Rukiah, 2009).

Pentingnya pijat oksitosin ini untuk mempercepat proses persalinan agar tidak berlangsung lama dan terjadi komplikasi persalinan (Suwondo \& Wahyuni, 2013). pijat oksitosin ini dapat dilakukan oleh keluarga dengan pendampingan bidan sebelumnya, sehingga mudah untuk dilakukan di rumah setelah persalinan yang bermanfaat untuk memperlancar produksi ASI (Wijayanti, 2014).

\section{Metode}

Desain penelitian ini pra eksperimental (static-group comparation design) dengan pendekatan kohort, populasinya seluruh ibu bersalin normal di BPM ASRI Tuban bulan februari - mei 2019 sejumlah 60 responden, dengan menggunakan teknik sampling sistematik random sampling didapatkan jumlah sampel 52 responden terdapat kelompok kontrol (26 responden) dan kelompok eksperimen (26 responden). Variabel independen Pijat oksitosin sedangkan variabel dependen frekuensi his, durasi his. Pijat oksitosin dilakukan selama 3 menit dan dapat diulang 3 kali. Kemudian dilakukan pengukuran his (frekuensi dan durasi his) setelah 10 menit dilakukan pijat oksitosin. Untuk kelompok kontrol, pengukuran frekuensi his dan durasi his dapat dilakukan setelah 30 menit pertama observasi kemajuan persalinan. Analisa data menggunakan independent sample t-Test dengan SPSS Vs 23.

\section{Hasil dan Pembahasan}

Tabel 1. Distribusi Responden berdasarkan Frekuensi His ibu Inpartu di BPM ASRI Tuban Bulan Februari-Mei 2019 
Tabel 1. Distribusi Responden berdasarkan Frekuensi His ibu Inpartu di BPM ASRI Tuban Bulan Februari-Mei 2019

\begin{tabular}{|c|c|c|c|c|c|c|c|}
\hline & & & $\bar{F} \mathbf{x}$ & nen $\leqslant i$ & & & Iot:al \\
\hline & & $\mathrm{Kr}^{1}$ & $\mathrm{Frali}^{2}$ & $\mathrm{~K}^{3} \mathrm{ili}$ & $\begin{array}{c}4 \\
\mathrm{~K}=1 \mathrm{i}\end{array}$ & $\mathrm{Frli}^{5}$ & \\
\hline $\begin{array}{l}\text { Pijat } \\
\text { olesitos } \\
\text { in }\end{array}$ & $\begin{array}{l}\text { Ekesperi } \\
\text { men }\end{array}$ & 0 & $\frac{2}{7}, 70$ & $\begin{array}{l}10 \\
38=5 \\
30\end{array}$ & $\begin{array}{l}14 \\
39.8 \\
39\end{array}$ & 00 & $\begin{array}{l}26 \\
100 \\
36\end{array}$ \\
\hline & Fontrol & 00 & $\begin{array}{l}9 \\
34,6\end{array}$ & $\begin{array}{l}11 \\
42.3 \\
36\end{array}$ & $\frac{6}{23}=1$ & 00 & $\begin{array}{l}26 \\
100 \\
96\end{array}$ \\
\hline Total & & 00 & $\begin{array}{l}11 \\
21,2\end{array}$ & $\begin{array}{l}21 \\
40,4 \\
96\end{array}$ & $\begin{array}{l}20 \\
38\end{array}$ & 00 & $\begin{array}{l}52 \\
100 \\
90\end{array}$ \\
\hline
\end{tabular}

Tabel diatas dapat diketahui bahwa hormon oksitosin (Kurniawan et al., 2017). Frekuensi his pada kelompok eksperimen Oksitosin sendiri merupakan suatu hormon sebagian besar 14 responden $(53,8 \%)$ yang dapat memperbanyak masuknya ion mendapatkan Frekuensi his 4 kali dalam 10 kalsium kedalam intra sel. Dengan dikeluarmenit.

Dengan melalui analisis data Uji Sample tTest (Independent sample t-Test) derajat kemaknaan $\alpha=0,05$. Hasil uji statististik menggunakan Uji Sample t-Test (Independent sample t-Test) diperoleh $\mathrm{p}$ value $=0,006$ ( $p$ value $<0,05)$. Hal tersebut menunjukan bahwa ada Pengaruh Pijat Oksitosin terhadap Frekuensi His pada Ibu inpartu di BPM ASRI Tuban Tahun 2019.

Mekanisme terjadinya kontraksi atau his pada persalinan kala I secara fisiologis dapat dipengaruhi renggangan dinding uterus (Mutmainnah, Johan, \& Llyod, 2017), rangsangan terhadap flesus saraf frankenhauseryang tertekan masa konsepsi dan dan akibat kerja kannya hormon oksitosin akan memperkuat ikatan aktin dan myosin sehingga kontraksi uterus akan semakin kuat, dalam hal ini sesuai dengan teori pijat oksitosin yang dilakukan pada ibu inpartu dapat meningkatkan kontraksi uterus (Suwondo \& Wahyuni, 2013).

Berbeda dengan kelompok kontrol hanya ada 11 (42,3\%) responden yang mengalami frekuensi kontaksi 3 kali dalam 10 menit dikarenakan tidak adanya tambahan rangsangan keluarnya hormon oksitosin yakni pijat oksitosin, akan tetapi pada kelompok kontrol juga ada yang mengalami frekuensi 4 kali dalam 10 menit namun jumlahnya tidak banyak hanya $6(23,1 \%)$ responden 
Pengaruh pijat oksitosin terhadap frekuens His, durasi His ...

Tabel 2. Distribusi Responden berdasarkan Durasi His pada ibu Inpartu di BPM ASRI Tuban Bulan Februari-Mei 2019

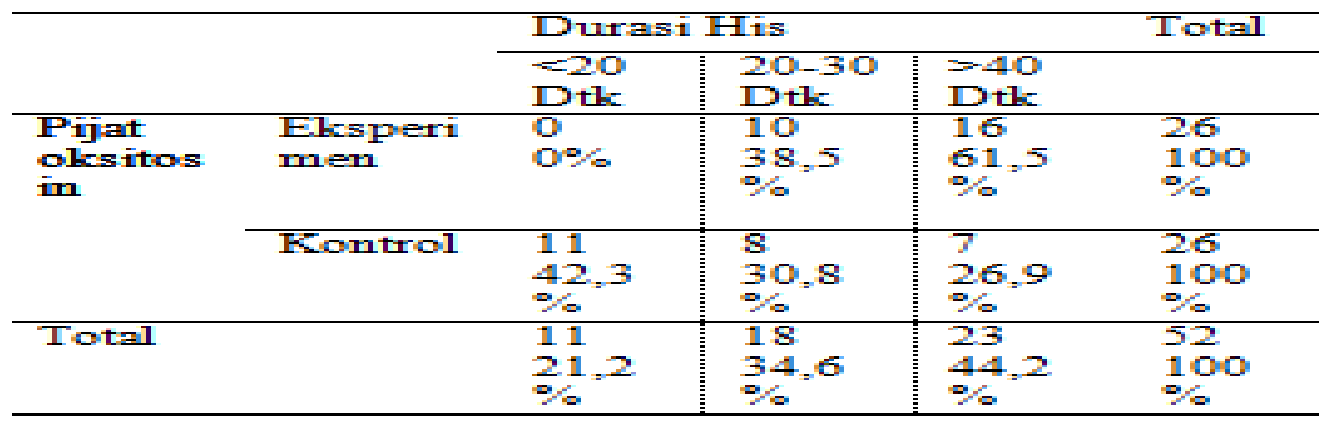

Tabel diatas dapat diketahui bahwa durasi his pada kelompok eksperimen sebagian besar 16 responden $(61,5 \%)$ mendapatkan durasi his $>40$ detik

Dengan melalui analisis data Uji Sample tTest (Independent sample t-Test) derajat kemaknaan $\alpha=0,05$. Hasil uji statististik menggunakan Uji Sample t-Test (Independent sample t-Test) diperoleh $\mathrm{p}$ value $=0,004$ ( $p$ value $<0,05)$. Hal tersebut menunjukan bahwa ada Pengaruh Pijat Oksitosin terhadap durasi His pada Ibu inpartu di BPM ASRI Tuban Tahun 2019

Pijat oksitosin dapat berdampak pada durasi his, secara fisiologis penyebab yang pasti dari mulai timbulnya kontraksi tidak diketahui dan mungkin karena pengaruh dari oksitosin (hormon yang dilepaskan oleh kelenjar hipofise dan menyebabkan kontraksi uterus selama proses persalinan) (Astuti, 2013).
Pijat oksitosin merupakan suatu rangsangan pada kedua sisi tulang belakang untuk merileksasi tingkat ketegangan dan kecemasan pada ibu inpartu sehingga mengakibatkan reflek okstosin meningkat (Widiyanti, Setyowati, Sari, \& Susanti, 2014)

Berdasarkan hasil penelitian kelompok eksperiment, pijat oksitosin dapat merangsang hormon oksitosin yang menyebabkan kontraksi uterus sehingga mempermudah lahirnya plasenta (Astuti, 2013)

Massage merupakan salah satu intervensi atau penatalaksanaan non farmakologis untuk mengurangi ketidaknyaman ibu bersalin dan membantu ibu bersalin menjadi rileks (Turlina \& Eka Ratnasari, 2016). relaksasi ini bertujuan menurunkan kadar epinefrin dan non epinefrin dalam darah sehingga adanya keseimbangan (equilibrium) (Boediman \& Desnawati, 2019), selain itu pemijatan pada bagian punggung dapat merangsang pengeluaran hormon en- 
dorphin (Azizah, Widyawati, \& Anggraini, 2011), sedangkan endorphin dapat berfungsi sebagai ejektor dan rasa rileks dapat menimbulkan ketenangan (Pratimi, Ernawati, \& Saudia, 2020), dapat mengurangi ketegangan otot, dalam penelitian ini pemijatan dilakukan pada tulang belakang yang merupakan daerah yang mudah terjadi penegangan otot ketika kelelahan sehingga pemijatan ini dapat meningkatkan produksi ASI (Khonsary, 2017)

\section{Kesimpulan}

Terdapat pengaruh pijat oksitosin terhadap Frekuensi his dan durasi his pada ibu inpartu di BPM ASRI Tuban, diharapkan pada tenaga kesehatan khususnya para bidan dapat menerapkan pijat oksitosin pada persalinan kala I yang mana akan memperlancar proses persalinan dan dapat mengurangi kejadian kematian ibu.

\section{Daftar Pustaka}

A.R, Pamingki Ritno, Yuniastini, T. A. (2016). Faktor Yang Berhubungan Dengan Kejadian Partus Lama. Jurnal Keperawatan:

Astuti, M. dan A. P. (2013). Perbedaan Lama Kala I Fase Aktif Pada Ibu Bersalin yang Dilakukan dan yang Tidak Dilakukan Pijat Endorphin di RB Margo Waluyo Surakarta. Jurnal Kebidanan STIKES Ngudi Waluyo.

Azizah, I. N., Widyawati, M. N., \& Anggraini, N. N.
(2011). Pengaruh Endorphin Massage Terhadap Intensitas Nyeri Kala I Persalinan Normal Ibu Primipara di BPS S dan B Demak Tahun 2011. Kebidanan.

Boediman, L. M., \& Desnawati, S. (2019). The Relationship between Parenting Style and Children's Emotional Development among Indonesian Population. Jurnal Ilmiah Psikologi MIND SET.

Cunningham. (2015). Kehamilan dan Persalinan. Kesehatan.

Kemenkes RI. (2013). Kehamilan, Persalinan, dan Nifas Normal. Buku Saku Pelayanan Kesehatan Ibu Di Fasilitas Kesehatan Dasar Dan Rujukan.

Khonsary, S. (2017). Guyton and Hall: Textbook of Medical Physiology. Surgical Neurology International.

Kurniawan, A., Santamaria, E. K., Operario, D., Tarkang, E. E., Zotor, F. B., Cardoso, S. R. de S. N., ... Volk, J. E. (2017). Asuhan Kebidanan Persalinan dan Bayi Baru Lahir. BMC Public Health.

Mochtar, R. (2011). Sinopsis Obstetri Jilid I. 2011.

Mutmainnah, A. U., Johan, H., \& Llyod, S. S. (2017). Asuhan Persalinan Normal dan Bayi Baru Lahir. Andi.

Pratimi, B. M. A., Ernawati, E., \& Saudia, B. E. P. (2020). Pengaruh Masase Endorphin Terhadap Peningkatan Produksi Asi Pada Ibu Post Partum Di Wilayah Kerja Puskesmas Bagu. Jurnal Midwifery Update (MU).

Qonitun, U., \& Betalia, B. (2018). Pengaruh Terapi Murottal Terhadap Tingkat Kecemasan Pada Ibu Bersalin Normal di Polindes Permata Bunda Kelurahan Perbon Kecamatan Tuban Kabupaten Tuban. Jurnal Kebidanan. 
Riyanto. (2014). Faktor-faktor yang Berhubungan dengan Partus Lama di Puskesmas Poned Kabupaten Lampung Timur. Jurnal Kesehatan Metro Sai Wawai.

Rukiah, A. Y. dkk. (2009). Asuhan Kebidanan II Persalinan. TIM.

Sofia, D. (2017). Pengaruh Pijat Oksitosin Terhadap Proses Involusi Uterus The Effect Of Oxytocin Massage To Involution Uterine Process. Journal Oksitosin Kebidanan.

Studi, P., Keperawatan, I., Perintis, S., \& Bakti, K. (2016). JURNAL IPTEKS TERAPAN Research of Applied Science and Education V9.i4 (282-293). Jurnal Ipteks Terapan.

Suwondo, A., \& Wahyuni, S. (2013). Efektifitas Kombinasi Pijat Oksitosin Tehnik Effleurage Dan Aromaterapi Rose Terhadap Kadar Prolaktin Post Partum Normal Di Puskesmas Dawe Kudus Tahun 2013. Jurnal Ilmiah
Bidan.

Turlina, L., \& Eka Ratnasari, N. V. (2016). Pengaruh Kompres Dingin Terhadap Penurunan Nyeri Persalinan Kala I Fase Aktif Di Bps Ny. Mujiyati Kabupaten Lamongan. Jurnal Kebidanan Dan Keperawatan Aisyiyah.

varney. (2010). Buku Ajar Asuhan Kebidanan. Hubungan ketuban pecah dini.

Widiyanti, F. A., Setyowati, H., Sari, K., \& Susanti, R. (2014). Perbedaan Antara Dilakukan Pijatan Oksitosin Dan Tidak Dilakukan Pijatan OksitosinTerhadap Produksi ASI Pada Ibu Nifas Di Wilayah Kerja Puskesmas Ambarawa. Journal Kebidanan Ngudi Waluyo.

Wijayanti, L. (2014). Pengaruh Pijat Oksitosin Terhadap Produksi ASI Pada Ibu Postpartum. Stikes Aisyiyah. 
This page itentionally left blank. 